Clayton, Beth V and Nabhani-Gebara, Shereen, When is it acceptable to allow a terminal patient to die? Pharmacy students' views from a London university. Journal of Oncology Pharmacy Practice, 27(3), pp. 521-530. Copyright (c) 2021 (Copyright Holder). DOI: https://doi.org/10.1177/1078155220921546 


\section{When is it acceptable to allow a terminal patient to die? Pharmacy students' views from a London University.}

\section{Introduction}

Accompanied suicide is illegal in the UK under the terms of the Suicide Act (1961). If found to be assisting a family member or loved one to end their life, such person(s) may be punished by up to 14 years imprisonment ${ }^{1,2}$. If a doctor is found to be involved in deliberately ending a patient's life then they could be charged with manslaughter, or even murder - the maximum penalty of which is life imprisonment ${ }^{1}$.

Although it is not yet legal in the UK, there are many ongoing debates regarding whether it should be legalised in the near future. Organisations such as Dignity in Dying regularly campaign to allow the option of assisted dying for 'terminally ill, mentally competent adults ${ }^{3}$. Recently the Royal College of Physicians have dropped their opposition of accompanied suicide, now adopting a neutral stance ${ }^{4,5}$, and the increase in coverage has prompted both the Royal College of General Practitioners and the British Medical Association to survey their members on the topic. Both associations are currently opposed to a change in the law ${ }^{6,7}$. It was also mentioned in Parliament in July 2019, with more debates on the topic sure to follow in the near future.

Currently, accompanied suicide is legal in 4 countries in Europe. Switzerland, where DIGNITAS was founded; defined as an organisation with the 'objective on ensuring a life and a death with dignity for its members. ${ }^{8}$ DIGNITAS accepts terminally ill people from all over the world, with over ' 7100 members in 69 different countries' ${ }^{8}$, including the UK. The Netherlands legalised euthanasia in 2001 and practice with strict condition that patient's suffering must be 'unbearable and without prospect of improvement (hopeless)' , although services in The Netherlands are not strictly patients with terminal illnesses. There have been a few cases involving patients with severe mental health issues (such as depression) and dementia. Luxembourg, who passed a law that came into action in 2009, states that patients with either an incurable medical condition leading to unbearable physical or mental suffering, or making end-of-life arrangements may be able to file a request for euthanasia or assisted suicide ${ }^{10}$. Finally, Belgium amended their law on euthanasia in 2014 to enable euthanasia of a child, making them the only country in the world to legalise child euthanasia where the child must actively request it and have the capacity to understand the implications ${ }^{11}$. It is also legal in Victoria, Australia, Canada, Colombia and 9 states in the US (with Maine becoming the tenth in 2020).

If the UK were to legalise accompanied suicide, then pharmacists will have a role in supplying and dispensing the medication to deliberately end a patient's life. Therefore, there should be adequate teaching on the topic to pharmacy students to ensure they have the knowledge to answer queries and handle dilemmas they may face with a new law. Moreover, conversations and teaching in pharmacy will enable pharmacists (and students) to confidently voice their opinions on accompanied suicide and their reasoning.

\section{Defining Euthanasia}

The definition of euthanasia can be easily confused as there are varying opinions and many different terms to describe specific processes. Terms accepted and defined by the non-profit organisation DIGNITAS include:

- 'Accompanied suicide - compromising elements of assistance with a self-determined end of life and accompaniment of dying patients ${ }^{12}$.' 
- 'Direct active euthanasia on express request (voluntary euthanasia) - the person wishing to end his/her own life requests and permits a third person to put an end to his/her life ${ }^{12}$.'

An additional term, suggested by the UK campaign Dignity in Dying is:

- Assisted dying - 'a term used to describe when a terminally ill, mentally competent adult, making the choice of their own free will and after meeting strict legal safeguards, takes prescribed medication which will end their life. ${ }^{\prime 3,13}$

Confusion on the definitions alone shows that the UK does not have advanced knowledge on accompanied suicide (and likewise terminology); suggesting pharmacists in the UK will also be lacking an understanding of the topic.

\section{Accompanied Suicide and Related Topics in Pharmacy Education}

Any potential confusion surrounding accompanied suicide, and related topics such as end-oflife and palliative care, in the pharmacy community may be partly explained due to potential lack of education and understanding of terminology - if the students are less educated on these topics, they could be less likely to feel comfortable with playing a part in the process.

Very few studies have been completed with pharmacists and/or pharmacy students on their knowledge surrounding accompanied suicide; and whilst there are more studies on end-of-life and palliative care, those results have been lacklustre.

End-of-Life and Palliative Care Education in US Pharmacy Schools ${ }^{14}$

Dickinson's 2012 study on the education of end-of-life and palliative care in pharmacy schools in the US found that education on this topic is deficient within pharmacy curricula. The study involved a fixed-choice questionnaire sent to 125 pharmacy schools in the US. Results found only ' $10 \%$ of pharmacy schools offered a "separate course" on dying and death' 14 and ' $18 \%$ said that death and dying is "not taught formally""14. Dickinson also found there to only be ' $54 \%$ US pharmacy schools covering euthanasia as a topic' ${ }^{14}$, showing that even in a country where euthanasia is legal in 10 states (from 2020), the education given to pharmacy students is very basic (if educated at all). This study identified a gap in pharmacy education on accompanied suicide, and no other similar studies have been conducted elsewhere. 


\section{Aim}

The primary aim of this study was to inform current education of final year MPharm (Master of Pharmacy) students and explore their views on accompanied suicide and the influencers that may affect one's views. Both patient and participant factors were explored to determine any influence over their views, including their knowledge on accompanied suicide.

\section{Methodology}

\section{Overview}

This project was an anonymous cross-sectional cohort study consisting of an online survey to explore the perceptions of final year Kingston University (KU) pharmacy students. The survey was open from January-March 2019 and was available via SurveyMonkey. Elements from other surveys used in previous studies (referenced above) were incorporated into this survey to ensure the questions were in an appropriate and concise manner.

There were found to be 139 final year students at $\mathrm{KU}$, therefore (assuming the confidence levels were $95 \%$ and the intervals $5 \%$ ) the minimum sample size required for this study to be significant to the population was 103 , using the SurveyMonkey sample size calculator. Due to the sensitive nature of the study, it was imperative to seek ethical approval from the SEC faculty committee of KU - this was granted January 2019.

\section{Survey Outline}

The survey was separated into the following three sections:

\section{Section A}

This section involved asking the participants to choose the correct definition of 'voluntary euthanasia', 'accompanied suicide', and 'assisted dying' from the definitions listed, with the actual definitions of all 3 revealed using the official definitions by DIGNITAS and Dignity in Dying. Furthermore, there were 3 questions asking whether they thought the above terms were legal in the UK, with their answer prompting information to be given on the law of accompanied suicide in the UK.

The aim of this section was to determine how educated the participants were on accompanied suicide and likewise terms - something that could be addressed and taught in pharmacy cohorts in the future.

\section{Section $B$}

This section consisted of four real-life vignettes of patients with terminal illnesses who showed a desire to end their lives via accompanied suicide. These patients varied in their illnesses, gender, and their age. As their illnesses varied, their mental capacity and ability to selfadminister medication may have also been questioned by the participants. Nevertheless, it was suggested that each patient's level of pain would not have improved from that point onwards, they were terminally ill and were therefore not expected to survive the next 12 months, and that they were not being coerced or blackmailed in any way to end their life. Moreover, a trigger warning was displayed before the cases were shown to the participant; warning them that the next topics involved terminal illnesses and patients requesting accompanied suicide, so if the topic was too sensitive, they could back out before being exposed to it. Had the participant chosen to proceed, a short abstract about the patient case 
was shown before receiving a series of statements to answer. The full case studies can be found in Appendix A.

- Case study 1 involved a 29-year-old female with terminal brain cancer, with full mental capacity and the ability to self-administer the lethal medication.

- Case study 2 consisted of a 67-year-old male with motor neurone disease (MND) who had full mental capacity, however, may not be able to self-administer the lethal medication.

- Case study 3 involved a 60-year-old male with terminal liver cancer who had the ability to self-administer the lethal medication; however his mental capacity was deteriorating (after requesting accompanied suicide with full mental capacity).

- Finally, case study 4 included a 14-year-old female with end-stage cystic fibrosis (CF). She had full mental capacity for a child of her age and was able to administer the lethal medication.

The statements were Likert-scale styled, including the choices - strongly agree, agree, neither agree nor disagree, disagree, and not sure. An example of such statements given is: 'I agree with the patient's request to end their life via accompanied suicide'. Additional Likert-style statements were introduced to determine the reasoning behind the participant's decision, ranging from a personal limitation (i.e. their own knowledge on the topic), to the patient in question (i.e. their age, gender, illness, mental capacity, etc.). To ensure validation of the answers, some of the questions were repeated in a similar manner.

The reasoning behind these questions was to determine both the personal and professional opinions of the participants and to understand whether they would differ with each case presented to them in the previous section. This also determined personal or patient-specific factors that may influence the participant's opinion.

\section{Section $C$}

This section included the demographics of the participants, such as their age, gender, their postal code (aka home-time address), ethnicity, and their religion. The latter of the demographics expanded if the participant answered that they identify with a religion; enabling them to develop on whether they felt that they actively follow their religion on a day-to-day basis. This then prompted a further question to ask how much of an influence they believe their religion could have had on their personal opinions expressed in section $B$. This could gauge a deeper insight into the personal beliefs/traits that may conflict with values of a healthcare professional, and how these could be discussed in the future.

Furthermore, questions regarding the content of their MPharm course, and their past experience with a loved one were included to understand the previous exposure the participants may have had on the topic.

\section{Statistical analysis}

Data analysis consisted mostly of descriptive statistics using Statistical Package for the Social Sciences (SPSS) statistics, consisting of a range of tabulations and graphs with chi-squared testing to determine the level of significance. 


\section{Results}

N.B. any Likert scale results have combined 'strongly agree' with 'agree' responses, and 'strongly disagree' with 'disagree' responses. Data has been numbered in Likert scales, where $1=$ agree, $2=$ neither agree nor disagree, $3=$ disagree, and 4 = not sure. P-values have been labelled as 'Sig.'

The data collected yielded a total 111 responses of a possible 139 (80\% response rate), with 25 surveys left incomplete. This gave a completed response rate of $62 \%$, though all responses were analysed. All tables and SPSS cross-tabulations are also displayed in the Appendices A-C.

\section{Demographics}

Of 111 responses, 58 were female and 24 were male (table 1). The remainder either preferred not to say or did not respond. As expected, $79 \%(n=68)$ respondents were between the ages of $18-24$ (61.3\% of the unspecified responses are also included).

The most frequent ethnicities were Asian $(n=34)$, Black $(n=17)$ and Arab $(n=15)$. The home-time postal code of students was asked to determine their usual address when they are not at university. 53.2\% $(n=59)$ students asked were originally from London, with $11.6 \%(n=13)$ from Southern regions of the UK, $7.2 \%(n=8)$ from Northern regions (including Yorkshire and The Humber) and only $2.7 \%(n=3)$ respondents living internationally.

Almost $70 \%$ ( $n=76)$ responses identified with a religion (46 of those describing themselves as Muslim). Of those $70 \%$ who said they were religious, just under $80 \%$ ( $n=63$ ) also said they currently practice their religion (figure 1$)$ and $58.2 \%(n=46)$ believed their religion to influence their opinions on accompanied suicide (figure 2).

A complete table of demographics can be found in Appendix B (Table 1, Figure 1 and 2). 


\section{Knowledge of MPharm students}

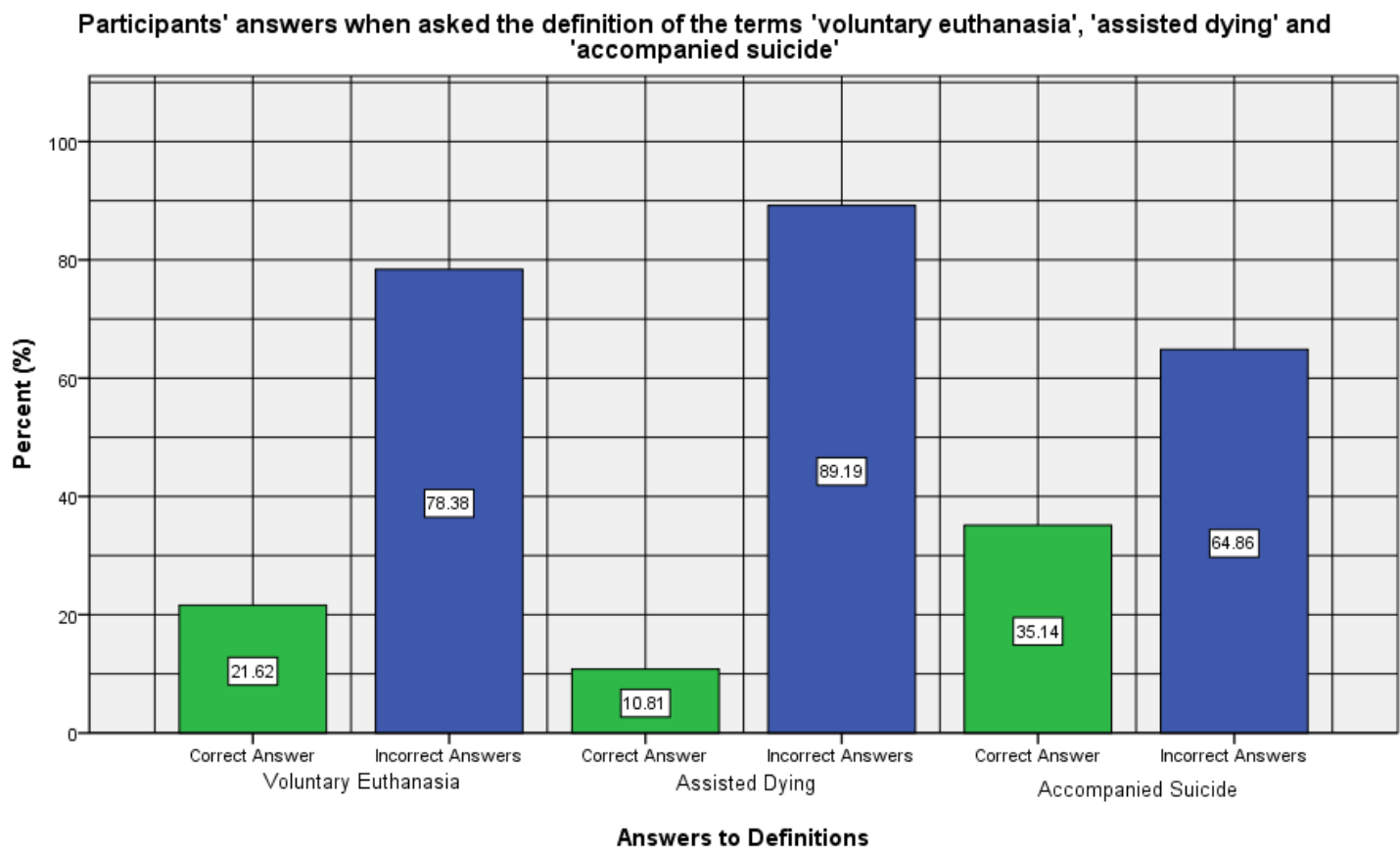

Figure 3 participants' answers to each question regarding the definition of the terms given to them. The terms were 'voluntary euthanasia', 'assisted dying' and 'accompanied suicide'.

Figure 3 represents the percentage of correct and incorrect answers of each definition. Regarding the term 'voluntary euthanasia', only $21.6 \%(n=24)$ could correctly determine the matching definition. This value fell to $10.8 \%(n=12)$ when defining 'assisted dying' but rose to $35.1 \%(n=39)$ when defining 'accompanied suicide'. 


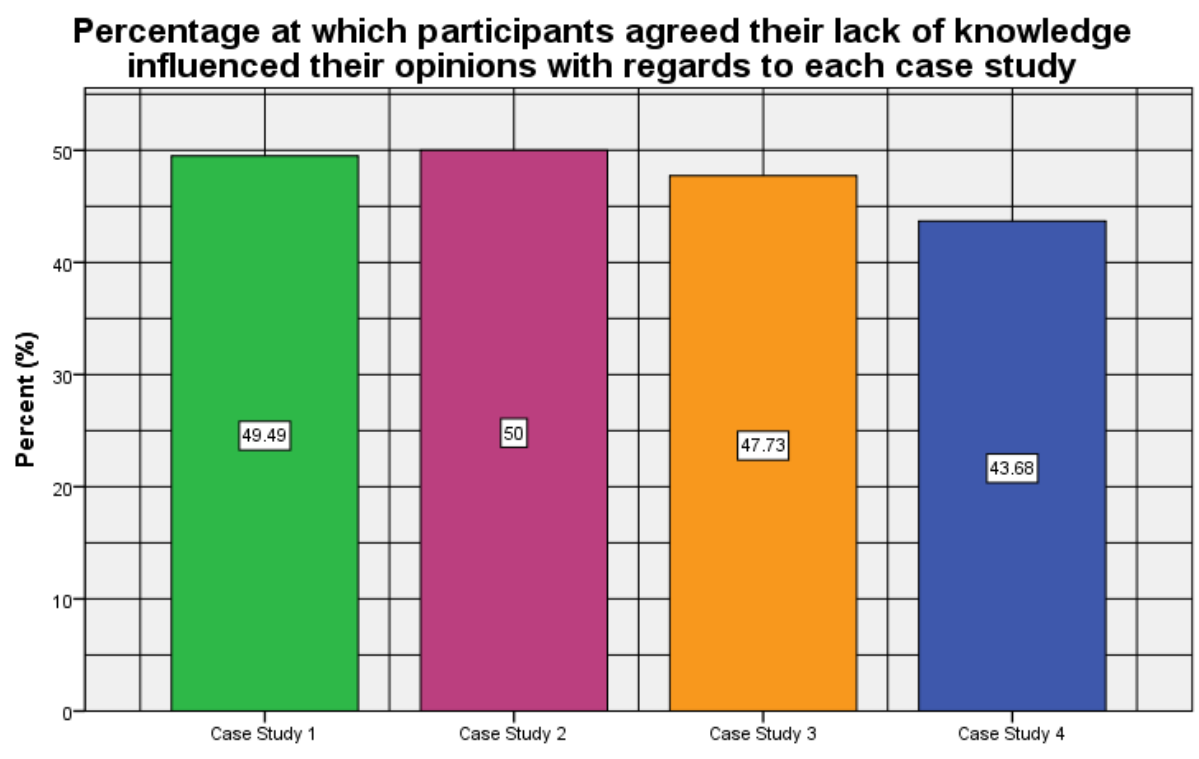

'Agree' Responses

Figure 4 percentage at which participants of the study said they agreed that their lack of knowledge influenced their opinions on accompanied suicide in each case study (excluding 'unspecified' results)

Additional to the definition matching exercise presented to them in Section A, the participants were also asked if they believed their lack of knowledge to influence their views on accompanied suicide in each case study. Figure 4 shows the percentage of participants who agreed to this statement with regards to each case study. Almost $50 \%$ of participants in every case stated that their lack of knowledge did influence their opinions.

Furthermore, participants were asked if they believed that they had been taught the aspects of accompanied suicide on their course, and if this had influenced their opinions. Most results found no link between the two.

\section{The Law}

Conversely, most participants $(93.7 \%, n=104)$ were able to correctly identify that all three practices given to them were illegal in the UK (table 2). There were no incomplete responses in section $A$. 


\section{The Personal Views}

One of the main aims of this study was to determine the opinions of pharmacy students on accompanied suicide in relation to specific vignettes. The full tables can be found in Appendix $\mathrm{C}$ (Tables 3 and 4).

\section{Participants' opinions on accompanied suicide with regards to each case study}

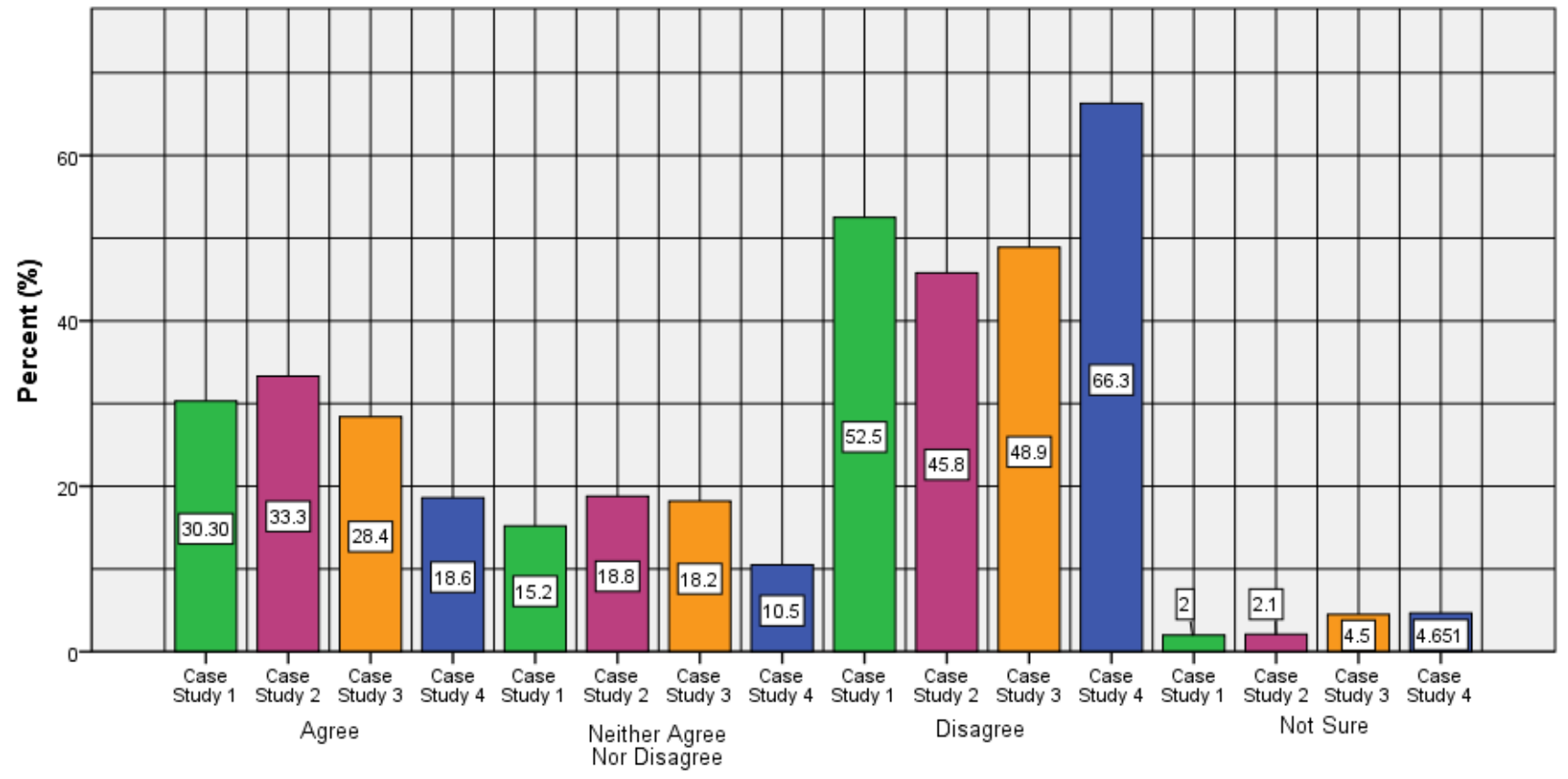

Opinions on Accompanied Suicide

Figure 5 participant's opinions on accompanied suicide with regards to each case study (excluding 'unspecified' results), where green $=$ case 1, purple $=$ case 2 , orange $=$ case 3, blue $=$ case 4.

Figure 5 demonstrates the views of participants on accompanied suicide as a bar graph (in percentage form). The graph shows a general opposition to accompanied suicide with all 4 cases - the case with the largest opposition being case 4 (14-year-old female with end-stage CF) with $66.3 \%(n=57)$ of 86 responses.

\section{The Influential Factors}

N.B. Chi-square results are determined by two-by-two categorical data-in each of the results, only 'agree' and 'disagree' responses were measured. All other responses were discounted.

An additional main aim of this study is to determine the specific factors that may influence one's views on accompanied suicide. Such factors can be broken down into two categories patient and participant factors. 


\section{The Patient Factors}

The patient factors are specific to the case study, where the features of the patient themselves may influence the opinion of the participant: examples of the factors that were measured include:

- Gender

- Age

- Terminal condition

- Ability to self-administer medication

- Current mental capacity

Responses were culminated to determine the patient factor in each case that would have been most likely to influence participants' opinions.

The greatest influential patient factors of case study 1 (29-year-old female with metastatic brain cancer) were found to be the terminal disease the patient was suffering from (37.76\%, $n=37$ of 98 ), with the least influential factor found to be the gender of the patient, at only $7.2 \%$ ( $n=7$ of 97$)$.

Akin to case 1, case 2 (67-year-old male with MND) found the disease of the patient was found to be the greatest influence with $34.0 \%(n=32)$ of 94 responses agreeing this patient's disease affected their view on the request. The gender of the patient was, again, found to be the least influential factor for the participants' views - only $8.3 \%(n=8)$ of 96 responses agreed to this.

Case study 3 (60-year-old male with terminal liver cancer) had a slight change to the top influential factors, with a new factor, specific to this patient, practically level with the disease of the patient - the mental capacity of this patient was found to influence $36.4 \%(n=32)$ of 88 responses, and the disease influenced $37.1 \%(n=33)$ of 89 responses. The gender of the participant remained the least influential factor at $6.8 \%$ ( $n=6$ of 88 responses).

Lastly, case 4 (14-year-old female with end-stage CF) found a slight change in the results. As opposed to the previous cases, the most influential factor was found to be the age of the patient, with $44.2 \%(n=38)$ of 86 responses agreeing that her age affected their views. As with every other case, gender was found to be the least influential factor, with less than $7 \%(n=6)$ of 86 responses claiming it to influence their opinion.

\section{The Participant Factors}

Alongside the theory that patient factors may influence a participant's opinion, the participant's factors themselves may equally have an impact. Such factors include:

- Demographics
- Gender
- Age
- Ethnicity
- Postal Code
- Religiosity 
- Experience with terminal illness/accompanied suicide of a loved one in the past.

Chi-square tests were conducted to deduce the factors that are linked with the participant's view. All tables can be found in Appendix D (Tables 5-17). Of all demographics, the participants' religion was the only factor to have a statistically significant influence on their opinions on accompanied suicide with a p-value of $<0.05$.

\section{Discussion}

To our knowledge, this is the first study to investigate the education and opinions of pharmacy students on accompanied suicide.

\section{General Opinions}

Most participants disagreed with the request for accompanied suicide with each case study, which contrasts to recent studies carried out by the campaign for Dignity in Dying and Porter and Warburton's 2018 article on the evolution of the Royal College of Physicians' (RCP) views on AS. Dignity in Dying found $84 \%$ of people in Great Britain 'support a change in the law' ${ }^{15}$, and Porter and Warburton compared results results from 2006 and 2014 survey to discover the percentage of respondents answering a change in the legislation was not required had decreased from $73.2 \%(n=3741)$ to $62.5 \%(n=4179)^{16}$. The latest RCP survey (conducted in 2019) found even fewer respondents believing the RCP should be against a change in legislation $(43.4 \%, n=2988)$, resulting in an overall no majority view, changing the RCP's position to neutral ${ }^{5}$.

There are also differences between this study and both the 2000 study by Hanlon et al involving British community pharmacists and Terkamo-Moisio et al's 2016 paper on Finnish Nurses' Attitudes towards Euthanasia. Hanlon et al's paper found similar views to those found from the 2019 RCP survey on AS. The paper concluded of the 320 pharmacists questioned, ' $70 \%$ pharmacists agreed that it was a patient's right to choose to die, but the agreement reduced to $57 \%$ when asked about extending the right to choose to die to include the right to involve one's physician' ${ }^{17}$ - still a majority in agreement in comparison to this study. TerkamoMoisio et al's paper found $89.9 \%$ respondents $(n=901)$ believing a person must have the right to decide on their own death, and $74.3 \%$ accepting euthanasia as part of the Finnish healthcare ${ }^{18}$.

From the graph shown in figure 5, it is clear that case study 4 showed the greatest opposition towards the patient's request, whereas case 2 gave the greatest support. The differing patient factors could have influenced the variation in these results, such as their age, gender, illness etc.

\section{Pharmacy Undergraduate Curriculum}

The level of understanding of accompanied suicide and similar terms were found to be very poor amongst the MPharm students of KU. Section A of the survey showed that overall; most definitions chosen for each term by the participants were incorrect. An average of 86 (77.5\%) participants answered each of the questions regarding definition incorrectly, and only 2 (1.8\%) participants were able to correctly identify all three definitions - clearly showing a lack of education on the topic. A potential explanation for this may be due to various organisations defining terms differently, hence leading to confusion on the official definitions.

On the contrary, the participants seemed substantially more knowledgeable on the laws of accompanied suicide in the UK. This contradicts with the notion that participants are 
completely uneducated in accompanied suicide; however there is substantial evidence from this study to show the lack of knowledge in many other areas. Accompanied suicide has gained more awareness in the media, popular TV shows (such as Coronation Street), and cinematic movies (such as Me Before You) over recent years; potentially playing into the greater understanding of the laws associated.

Since the study was limited only to students at KU, it cannot be definitively concluded that all other universities would develop similar results - further studies will need to be conducted involving other universities across the UK to prove this conclusion. Should results stand similar at other universities, this could trigger more teaching on accompanied suicide; with the aim of educating future pharmacists on the topic and the processes involved were it to be legalised in the future. $\mathrm{KU}$ is also a very ethnically diverse university, and whilst results were able to reflect London quite accurately, it was not reflective of the rest of the UK.

\section{The Patient Factors}

In order to understand any variance of participant opinions between each case study, it was important to recognise the patient factors in each case and compare it to the opinions of the participants.

\section{General Factors}

Most patient factors explored did not play a significant role in the participants' opinions. Factors such as the gender and the ability to self-administer lethal medication showed no significance or influence.

The disease of the patient, whilst being found as one of the main patient factors to influence the participants' opinions, did not strongly point to any one specific disease. This may suggest confusion in pharmacy students with regards to certain diseases they may not be more exposed to (such as MND and CF). Case 3 also found the patient's declining mental capacity as one of the most influential factors, however it cannot be concluded that this would be statistically significant as it was only measured in one patient case.

\section{The Patient's Age}

It was decided to measure any connection between the patient's age and the opinion of the participant since studies conducted seemingly suggested that the public are more opposed to childhood accompanied suicide in comparison with adults.

Deak et al's 2015 study on child euthanasia aimed to determine the factors involved in opposition to the topic - including participant factors such as their religion. A total of 213 participants completed the questionnaire, with mostly Belgian participants $(79 \%)^{19}$. A question asked the participants how much they agreed with the new laws on child euthanasia in Belgium, discovering $71.8 \%$ accepted child euthanasia (with $50 \%$ agreeing if the motive was 'to end the severe suffering of seriously ill children $\left.{ }^{19}\right)$. Though this value showed the participants were quite accepting of child euthanasia, it was discovered to be lower than the acceptance towards adult euthanasia $(86 \%)^{20}$, found in a similar study conducted by the same authors ${ }^{20}$.

Though many factors were measured to determine the reasoning behind the participants' opinions in this study, one that was not included was their level of knowledge on euthanasia involved in children. It could be argued that since this was such a new legislation when the article was written, little could have been known about it among the participants, therefore their opinions may have been based more on the legislations they were already familiar with (i.e. adult euthanasia in Belgium). 
The 2015 study resulted in the varied ages in this study, from 67 (case 2) to a mere 14-yearsold (case 4). The influence of age in cases 1-3 remained rather insignificant, however case 4 found almost half of respondents stating the age of the patient to influence their opinions on her request to end her life. Considering the momentous opposition to case study 4's request for accompanied suicide, it would make sense to assume the young age of the patient substantially influenced the MPharm students' opinions on her request. More specifically, pharmacy students are more likely to disagree with a patient's request to end their life via accompanied suicide if they were a child.

If the UK were to ever legalise accompanied suicide in the future, the age of the patient should be taken into careful consideration. As problematic as the situation may be when involving a paediatric patient, it would be unacceptable to discriminate against a patient's wishes purely due to their age.

\section{The Participant Factors}

\section{General Factors}

As with the factors of the patient, the factors of the participant themselves could be found to play a significant role in their opinions. From the results found, it can be concluded that most of the participant factors measured did not have any statistically significant link to their opinions on each case study (gender, age, ethnicity, postal-code, past experience, and taught aspects). Some of these results may not, however, be accurate enough to draw a conclusion. For instance, as the majority of participants $(61.3 \%, n=68$ of 86$)$ claimed to be between the ages of 18-24, there may not be a sufficient variety of older ages to confirm this conclusion. For more accurate results, further studies should be undertaken including older generations of participants who had studied pharmacy (such as newly qualified and experienced pharmacists).

\section{The Participant's Religion}

Considering the widespread investigations into religiosity and ethical views, it was integral to include the participant's religion as a measurable factor. Of all the participant factors, this was the only statistically significant link against their opinions - tables 6, 9, 12, and 15 all display each $p$-value as $<0.05$. This can therefore conclude that pharmacy students who identify with a religion are more likely to be opposed to accompanied suicide, supporting previous literature. Moreover, this verifies that a pharmacy student who actively practices their religion is significantly more likely to disagree with a patient's request to end their life via accompanied suicide.

Additional studies gave similar findings between religion and opinions towards AS. Hussain and White's 2009 qualitative study on UK GP's views on the practice of physician-assisted suicide (PAS) and their specific role revealed some GPs recognising their personal aspects influencing their views, such as 'personal experience and religious teaching ${ }^{21}$, although they had stated their religion had not made them opposed to PAS, it was instead the 'concern regarding doing harm'21. Hanlon et al's study, however, found a 'significant association between those who declared a religious and/or ethnic background and a less favourable attitude to PAS ${ }^{17}$. Terkamo-Moisio et al also compared their results with the religiosity of the respondents. Similarly to Hanlon et al's conclusion, Terkamo-Moisio et al stated that 'Nurses' religiosity is widely recognised as a strong indicator of their attitudes towards euthanasia, correlating negatively with support for the practice ${ }^{18}$. 


\section{Limitations}

A few limitations arose in this study that could be improved in future studies. Firstly, only final year KU students from 2019 were surveyed, therefore not representative of final year MPharm students in London without considering the views of those around the rest of the UK who may have opposing opinions. Especially since London is an area with diverse religious beliefs, the more rural areas of the UK could present with a very different outlook on the topic.

As the study is limited to final year students, most participants will be between the ages of 2025 (barring a few mature students). This hence limits the results to a certain generation of people and does not well represent other generation's views. Recent articles by Dignity in Dying $^{4,15}$ and Royal College of Physicians ${ }^{5}$ suggest there has been a general increase in support towards accompanied suicide over the years, therefore there could be an even stronger opposition towards accompanied suicide with pharmacists who have been practicing for many years.

Finally, the patients involved in each vignette all had terminal illnesses (in the sense that they were expected to die in the next 12 months). Although this will still pose many diverse opinions, this questionnaire did not deliberate any patients with life-limiting illnesses that may not necessarily be deemed 'terminal' at that stage in the person's life. For instance, a patient diagnosed with rheumatoid arthritis who is in constant pain and is limited to doing certain everyday tasks, or a patient who has been newly diagnosed with a slowly deteriorating disease such as multiple sclerosis or dementia. These types of cases could pose an even more controversial and challenging decision as the patient could have a lot more of their life to live (even if the quality of their life is poor), which may affect the views of some people.

\section{Recommendations}

Considering the results obtained from this study, three following changes were recommended to improve the education of pharmacy students:

1. Approved definitions of accompanied suicide and likewise terms - one specific, certified medical organisation should approve clear and concise definitions of accompanied suicide and similar terms associated with it. These definitions should then be the set definitions understood in the UK, therefore avoiding confusion of the terminology (as is the current situation).

2. Including accompanied suicide in the pharmacy syllabus - this study concluded that future pharmacists in the UK are very uneducated on accompanied suicide; and since they will likely be exposed to patients with terminal illnesses at some stage in their careers, it would be logical to have some inclusion of accompanied suicide onto their syllabus. Whether accompanied suicide becomes legalised in the UK or not, this knowledge could be extremely beneficial in conversations with patients (or families of patients) who may ask questions revolving around end-of-life and accompanied suicide.

3. Inclusion of lesser known terminal illnesses in the pharmacy syllabus - whilst pharmacy students seem to have a good understanding of well-known terminal diseases in the UK (such as cancer and heart failure), they are less educated on less common terminal illnesses (such as MND, CF, MS etc.) A better understanding into these diseases at their terminal stages may enable pharmacy students to more confidently conclude their opinions on accompanied suicide in specific illnesses. 


\section{Future Work}

As this study was the first of its kind to involve pharmacy students, the hope is for the awareness of accompanied suicide and the role of the pharmacist to extend further to the rest of the UK, triggering further studies of a similar nature to cement conclusions into the education and opinions of pharmacy students and pharmacists. There is a possibility that accompanied suicide (or any other similar practice) could become legal in the UK in the future, so as well as enabling future pharmacists to answer queries of patients/patient's families with confidence, knowledge regarding accompanied suicide could become vital for ideal pharmacy practice.

This study will also be repeated on oncology pharmacists in the UK in the near future to understand their views and education on the topic, and hopefully will be able to evolve into a study for international pharmacists to compare the results (in both countries where accompanied suicide (or similar terms) is and is not legal).

\section{Conclusion}

Conducting this study has revealed the true lack of knowledge future pharmacists have on accompanied suicide, which may enable additional teaching on the topic in the MPharm degree in the future. Moreover, the study has shown most final year Kingston MPharm students would disagree with a patient's request to end their life via accompanied suicide (regardless of the patient's situation). Nevertheless, there has been shown to be certain influential factors of the patient affecting the views of the MPharm students, such as their age, the terminal illness they are suffering from, and even their mental capacity - probably influencing the views of pharmacy students due to the ethically problematic aspect of each feature. Additionally, it has concluded that religious participants are much more likely to oppose accompanied suicide compared with those that do not practice a religion.

The Authors declare that there is no conflict of interest. 


\section{References}

1. NHS. Euthanasia and assisted suicide. [Internet] 2017 [cited 2019 Apr 26]. Available from: https://www.nhs.uk/conditions/euthanasia-and-assisted-suicide/

2. Legislation.gov.uk. Suicide act 1961. [Internet] 1961 [cited 2019 Apr 26]. Available from: http://www.legislation.gov.uk/ukpga/Eliz2/9-10/60/section/2

3. Dignity in Dying. About us. [Internet] 2018 [cited 2018 Dec 09]. Available from: https://www.dignityindying.org.uk/about-us/

4. Dignity in Dying. Royal college of physicians will drop its longstanding opposition to assisted dying. [Internet] 2019 [cited 2019 Aug 22]. Available from:

https://www.dignityindying.org.uk/news/royal-college-physicians-drop-longstandingopposition-assisted-dying-neutral/

5. Royal College of Physicians. No majority view on assisted dying moves RCP position to neutral. [Internet]. 2019 [cited 2019 Apr 04]. Available from:

https://www.rcplondon.ac.uk/news/no-majority-view-assisted-dying-moves-rcpposition-neutral

6. RCGP. Assisted dying. [Internet] 2014 [cited 2019 July 8]. Available from: https://www.rcgp.org.uk/policy/rcgp-policy-areas/assisted-dying.aspx

7. BMA. Physician-assisted dying. [Internet] 2019 [cited 2019 July 8]. Available from: https://www.bma.org.uk/advice/employment/ethics/ethics-a-to-z/physician-assisteddying

8. DIGNITAS. Who is DIGNITAS. [Internet]. 2019 [cited 2019 Apr 26]. Available from: http://www.dignitas.ch/index.php?option=com content\&view=article\&id=4\&Itemid= 44\&lang=en

9. My Death My Decision. Euthanasia In The Netherlands - in practice. [Internet] 2018 [cited 2020 Jan 19]. Available from: https://www.mydeathmydecision.org.uk/info/assisted-dying-in-other-countries/euthanasia-in-thenetherlands/

10. Guichet.Iu. Information on requesting euthanasia or assisted suicide. [Internet] 2012 [cited 2020 Jan 19]. Available from: https://guichet.public.lu/en/citoyens/famille/euthanasie-soins-palliatifs/fin-devie/euthanasie-assistance-suicide.html.

11. Watson, R. Belgium extends euthanasia law to children. BMJ. [Internet]. 2014 [cited 2019 Apr 27]; 348. Available from: https://www.bmj.com/content/348/bmj.g1633

12. DIGNITAS. Lexicon. [Internet]. 2018 [cited 2018 Nov 29]. Available from: http://www.dignitas.ch/index.php?option=com content\&view=article\&id=31\&ltemid =71\&lang=en

13. Agespace. Assisted dying. [Internet]. 2019 [cited 2019 Apr 12]. Available from: https://www.agespace.org/care/end-of-life-planning-and-care/assisted-dying

14. Dickinson, G. End-of-life and palliative care education in US pharmacy schools. AJHPM. [Internet]. 2012 [cited 2019 Apr 09]; 30(6): 532-535. Available from: https://journals.sagepub.com/doi/full/10.1177/1049909112457011 
15. Dignity in Dying. Largest ever poll on assisted dying finds increase in support to $84 \%$ of Britons. [Internet]. 2019 [cited 2019 Apr 04]. Available from:

https://www.dignityindying.org.uk/news/poll-assisted-dying-support-84-britons/

16. Porter K, Warburton K. Physicians' views on current legislation around euthanasia and assisted suicide: Results of surveys commissioned by the Royal College of Physicians. Future Healthc J. [Internet]. 2018 [cited 2019 Oct 11]; 5(1): 30-34. Available from: https://www.ncbi.nlm.nih.gov/pmc/articles/PMC6510045/

17. Hanlon T, Weiss M, Rees J. British community pharmacists' views of physician-assisted suicide (PAS). Journal of Medical Ethics [Internet]. 2000 [cited 2018 Oct 20]; 26: 363369. Available from: https://www.ncbi.nlm.nih.gov/pmc/articles/PMC1733280/

18. Terkamo-Moisio A, Kvist T, Kangasniemi M, Laitila T, Ryynänen O-P, Pietilä A-M. Nurses' attitudes towards euthanasia in conflict with professional ethical guidelines. Nursing Ethics [Internet]. 2017 [cited 2018 Oct 20]; 24(1): 70-86. Available from: https://journals.sagepub.com/doi/full/10.1177/0969733016643861?url ver=Z39.882003\&rfr id=ori\%3Arid\%3Acrossref.org\&rfr dat=cr pub\%3Dpubmed

19. Deak, C. Saroglou, V. Terminating a child's life? Religious, moral, cognitive, and emotional factors underlying non-acceptance of child euthanasia. Psychologica Belgica. [Internet]. 2015 [cited 2019 Apr 27]; 57(1): 59-76. Available from: https://www.psychologicabelgica.com/articles/10.5334/pb.341/

20. Deak, C. Saroglou, V. Opposing abortion, gay adoption, euthanasia, and suicide: compassionate openness or self-centred moral rigorism? Arch for Psych of Relig. [Internet]. 2015 [cited 2019 Apr 27]; 37(3): 267-294. Available from: https://journals.sagepub.com/doi/10.1163/15736121-12341309

21. Hussain T, White P. GPs' views on the practice of physician-assisted suicide and their role in proposed UK legislation: a qualitative study. Br J Gen Pract. [Internet]. 2009 [cited 2019 Oct 11]; 59(568): 844-849. Available from: https://www.ncbi.nlm.nih.gov/pmc/articles/PMC2765836/ 


\section{Appendix}

\section{Appendix A - Case Studies:}

- Case 1 - A 29 year old female suffering from an aggressive malignant brain tumour wishes to end her life via accompanied suicide. In recent weeks she has been experiencing increasingly frequent and longer seizures, severe head and neck pain, and stroke-like symptoms. She is afraid of her brain tumour changing her behaviour and causing her pain during the last few months of her life so she has therefore requested accompanied suicide from her doctor. She has full mental capacity and she would also be able to self-administer the lethal medication.

- Case 2 - A 67 year old male suffering from the effects of Motor Neurone Disease (MND) wishes to end his life via accompanied suicide. He fears becoming entombed in his own body and experiencing a traumatic, drawn-out death so he has therefore requested accompanied suicide from his doctor. He currently has full mental capacity to make this decision, however due to his condition, he may not be able to self-administer the lethal medication.

- Case 3 - A 60 year old male with terminal liver cancer wishes to end his life via accompanied suicide. He has recently lost the use of his legs and is only able to crawl. He has also become very breathless, therefore he has requested accompanied suicide from his doctor. His mental capacity is declining and he is becoming increasingly confused, however he requested this decision when he had full mental capacity. He would be able to self-administer the lethal medication.

- Case 4 - A 14 year old female in the end stages of cystic fibrosis (CF) wishes to end her life via accompanied suicide. She is tired of living with the terminal disease which causes recurrent infections and tissue damage. Her breathing has become increasingly difficult, therefore she has requested accompanied suicide from her doctor. She has full mental capacity for a child her age and is able to self-administer the lethal medication.

\section{Appendix B - Demographics}

\section{Demographics Table:}

\begin{tabular}{|c|c|c|c|}
\hline & & $\begin{array}{l}\text { Count } \\
(n=111)\end{array}$ & Percentage (\%) \\
\hline \multirow[t]{6}{*}{ Gender } & Female & 58 & 52.3 \\
\hline & Male & 24 & 21.6 \\
\hline & Prefer Not to Say & 4 & 3.6 \\
\hline & Other & 0 & 0.0 \\
\hline & Unspecified & 25 & 22.5 \\
\hline & Total & 111 & 100.0 \\
\hline \multirow[t]{5}{*}{ Age } & $18-24$ & 68 & 61.3 \\
\hline & $25-34$ & 13 & 11.7 \\
\hline & $35-44$ & 4 & 3.6 \\
\hline & $45-54$ & 1 & 0.9 \\
\hline & $55-64$ & 0 & 0.0 \\
\hline
\end{tabular}




\begin{tabular}{|c|c|c|c|}
\hline & $65+$ & 0 & 0.0 \\
\hline & Unspecified & 25 & 22.5 \\
\hline & Total & 111 & 100.0 \\
\hline \multirow[t]{9}{*}{ Ethnicity } & White & 10 & 9.0 \\
\hline & Black & 17 & 15.3 \\
\hline & Mixed & 3 & 2.7 \\
\hline & Arab & 15 & 13.5 \\
\hline & Asian & 34 & 30.6 \\
\hline & Prefer Not to Say & 4 & 3.6 \\
\hline & Other & 3 & 2.7 \\
\hline & Unspecified & 25 & 22.5 \\
\hline & Total & 111 & 100.0 \\
\hline \multirow[t]{15}{*}{ Postal Code } & East & 0 & 0.0 \\
\hline & East Midlands & 1 & 0.9 \\
\hline & London & 59 & 53.2 \\
\hline & North East & 2 & 1.8 \\
\hline & North West & 5 & 4.5 \\
\hline & Northern Ireland & 0 & 0.0 \\
\hline & Scotland & 0 & 0.0 \\
\hline & South East & 8 & 7.2 \\
\hline & South West & 5 & 4.5 \\
\hline & West & 0 & 0.0 \\
\hline & West Midlands & 2 & 1.8 \\
\hline & Yorkshire and The Humber & 1 & 0.9 \\
\hline & International & 3 & 2.7 \\
\hline & Unspecified & 25 & 22.5 \\
\hline & Total & 111 & 100.0 \\
\hline \multirow[t]{4}{*}{ Religion } & Christian & 11 & 9.9 \\
\hline & Catholic & 3 & 2.7 \\
\hline & Orthodox & 2 & 1.8 \\
\hline & Jewish & 1 & 0.9 \\
\hline
\end{tabular}




\begin{tabular}{|c|c|c|c|}
\hline & Muslim & 46 & 41.4 \\
\hline & Buddhist & 2 & 1.8 \\
\hline & Hindu & 6 & 5.4 \\
\hline & Sikh & 3 & 2.7 \\
\hline & Atheist/Agnostic & 3 & 2.7 \\
\hline & Nothing in Particular & 4 & 3.6 \\
\hline & Prefer Not to Say & 3 & 2.7 \\
\hline & Other & 2 & 1.8 \\
\hline & Unspecified & 25 & 22.5 \\
\hline & Total & 111 & 100.0 \\
\hline Past Experience & Yes & 20 & 18.0 \\
\hline & No & 39 & 35.1 \\
\hline & Unspecified/Skipped & 52 & 46.8 \\
\hline & Total & 111 & 100.0 \\
\hline
\end{tabular}




\section{Religion Pie Charts:}

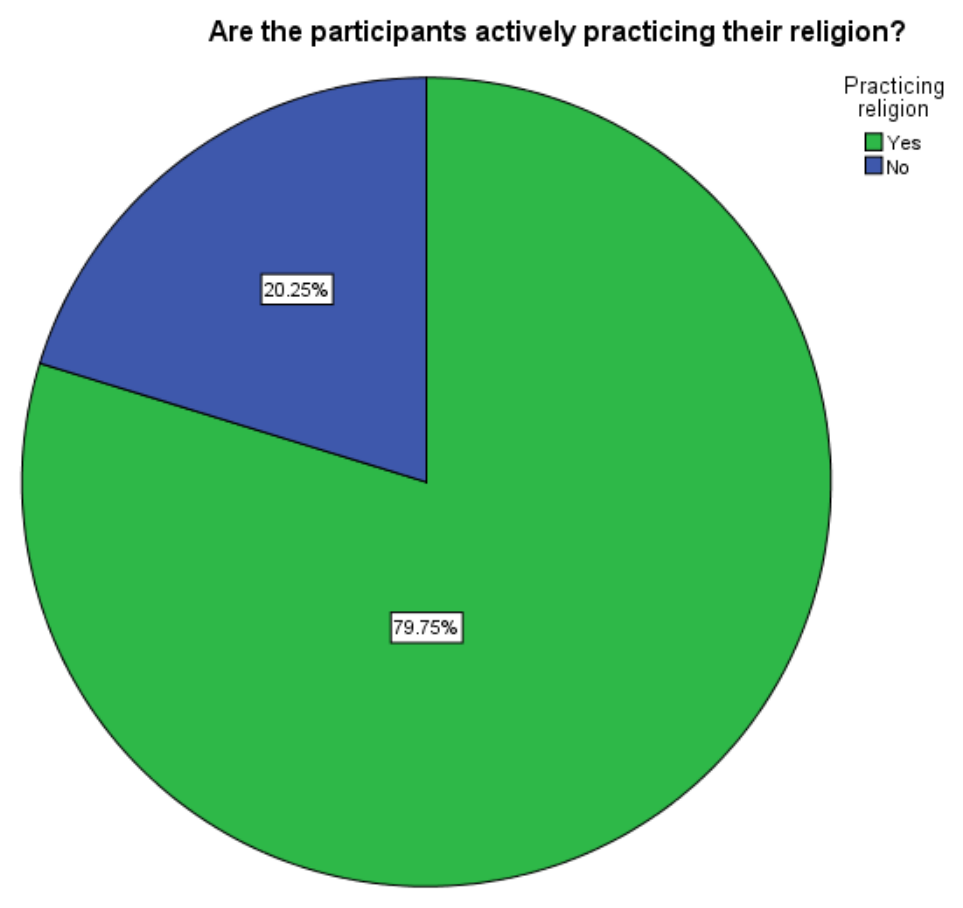

Figure 1 are participants actively practicing their religion?

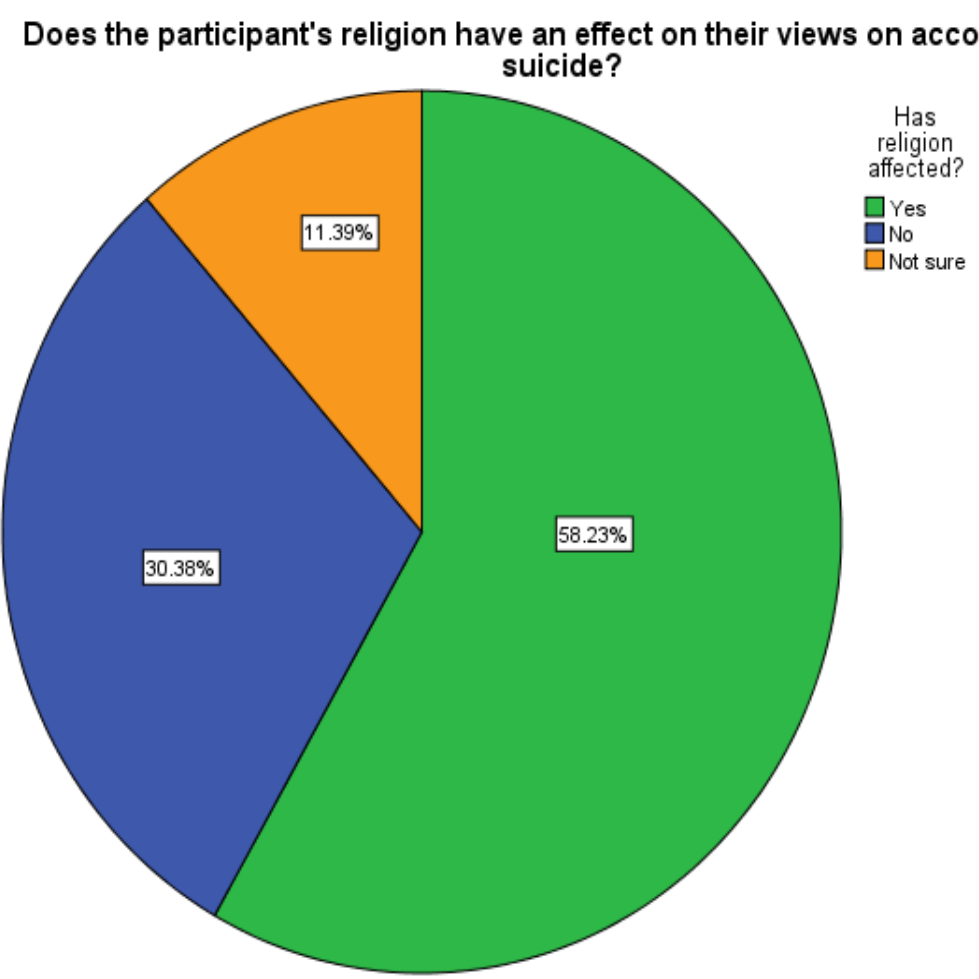

Figure 2 do participants believe their religion influenced their opinions of accompanied suicide? 


\section{Appendix C - Frequency Tables:}

\section{Section A:}

Law:

Is it legal in the UK?

\begin{tabular}{llll} 
& & Count $(\mathrm{n}=111)$ & Percent (\%) \\
\hline Voluntary Euthanasia & Yes & 5 & $4.5 \%$ \\
\cline { 2 - 4 } & No & 106 & $95.5 \%$ \\
\hline Assisted Dying & Yes & 12 & $10.8 \%$ \\
\cline { 2 - 4 } & No & 99 & $89.2 \%$ \\
\hline Accompanied Suicide & Yes & 5 & $4.5 \%$ \\
\cline { 2 - 4 } & No & 106 & $95.5 \%$ \\
\hline
\end{tabular}

Table 2 the laws on accompanied suicide and associated terms in the UK

\section{Section B:}

Opinions:

Opinions on Accompanied Suicide with each Case Study

\begin{tabular}{|c|c|c|c|}
\hline & & Count $(n=111)$ & Percent (\%) \\
\hline \multirow[t]{6}{*}{ Case Study 1} & Agree & 30 & 27.0 \\
\hline & Neither Agree nor Disagree & 15 & 13.5 \\
\hline & Disagree & 52 & 46.8 \\
\hline & Not Sure & 2 & 1.8 \\
\hline & Unspecified & 12 & 10.8 \\
\hline & Total & 111 & 100.0 \\
\hline \multirow[t]{6}{*}{ Case Study 2} & Agree & 32 & 28.8 \\
\hline & Neither Agree nor Disagree & 18 & 16.2 \\
\hline & Disagree & 44 & 39.6 \\
\hline & Not Sure & 2 & 1.8 \\
\hline & Unspecified & 15 & 13.5 \\
\hline & Total & 111 & 100.0 \\
\hline \multirow[t]{2}{*}{ Case Study 3} & Agree & 25 & 22.5 \\
\hline & Neither Agree nor Disagree & 16 & 14.4 \\
\hline
\end{tabular}




\begin{tabular}{|c|c|c|c|}
\hline & Disagree & 43 & 38.7 \\
\hline & Not Sure & 4 & 3.6 \\
\hline & Unspecified & 23 & 20.7 \\
\hline & Total & 111 & 100.0 \\
\hline \multirow[t]{6}{*}{ Case Study 4} & Agree & 16 & 14.4 \\
\hline & Neither Agree nor Disagree & 9 & 8.1 \\
\hline & Disagree & 57 & 51.4 \\
\hline & Not Sure & 4 & 3.6 \\
\hline & Unspecified & 25 & 22.5 \\
\hline & Total & 111 & 100.0 \\
\hline
\end{tabular}

Table 3 participant's opinions on each case study

\section{Descriptive Statistics}

\begin{tabular}{lllllllll} 
& N & Range & Minimum & Maximum & Mean & Std. Deviation & Variance \\
\hline Opinions on Case Study 1 & 99 & 3 & 1 & 4 & 2.26 & .921 & .849 \\
\hline Opinions on Case Study 2 & 96 & 3 & 1 & 4 & 2.17 & .925 & .856 \\
\hline Opinions on Case Study 3 & 88 & 3 & 1 & 4 & 2.30 & .937 & .877 \\
\hline Opinions on Case Study 4 & 86 & 3 & 1 & 4 & 2.57 & .848 & .719 \\
\hline
\end{tabular}




\section{Appendix D - Cross-Tabulation/Chi-Square Tests:}

(N.B. Results shown below grouped together 'strongly agree' with 'agree' responses and 'strongly disagree' with 'disagree' responses. Results shown not including 'unspecified', 'neither agree nor disagree', and 'not sure' responses. Results highlighted in yellow are statistically significant but may not be valid, results highlighted in green are statistically significant and valid.)

\section{Participant Factors:}

Case 1:

\section{Pearson Chi-Square Tests (Case Study 1)}

$$
\begin{array}{llll}
\text { Gender } & \text { Age } & \text { Ethnicity } & \text { Post Code }
\end{array}
$$

\begin{tabular}{lllllll}
\hline Opinions on Case Study 1 & Chi-square & 3.630 & .256 & .032 & .436 \\
\cline { 2 - 6 } & $\mathrm{df}$ & 1 & 1 & 1 & .859 \\
\cline { 2 - 6 } & Sig. & .057 & .613 & .509 \\
\hline
\end{tabular}

Results are based on nonempty rows and columns in each innermost subtable.

Table 5 Pearson Chi-Square tests for Case Study 1. Tests include the link between participant's opinions on the case study vs their demographics, such as gender, age, ethnicity and post code.

\section{Pearson Chi-Square Tests (Case Study 1)}

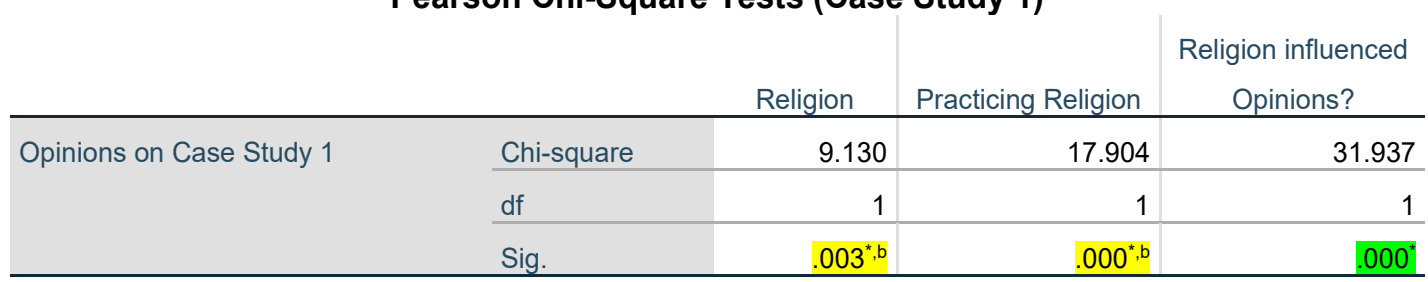

Results are based on nonempty rows and columns in each innermost subtable.

*. The Chi-square statistic is significant at the .05 level. 


\begin{tabular}{|c|c|c|}
\hline \multirow[t]{3}{*}{ Opinions on Case Study 1} & Chi-square & 1.514 \\
\hline & df & 2 \\
\hline & Sig. & .469 \\
\hline
\end{tabular}

Results are based on nonempty rows and columns in each innermost subtable.

Table 7 Pearson Chi-Square tests for Case Study 1. Tests include the link between participant's opinions on the case study vs their experience with terminal illness.

Case 2:

\section{Pearson Chi-Square Tests (Case Study 2)}

\begin{tabular}{llllll} 
& & Gender & Age & Ethnicity & Post Code \\
\hline Opinions on Case Study 2 & Chi-square & 3.245 & .084 & .454 & 1.457 \\
\cline { 2 - 6 } & df & 1 & 1 & 1 & .501 \\
\cline { 2 - 6 } & Sig. & .072 & .772 & .227 & 1 \\
\hline
\end{tabular}

Results are based on nonempty rows and columns in each innermost subtable.

Table 8 Pearson Chi-Square tests for Case Study 2. Tests include the link between participant's opinions on the case study vs their demographics, such as gender, age, ethnicity and post code.

\section{Pearson Chi-Square Tests (Case Study 2)}

\begin{tabular}{lllll} 
& & Religion & Practicing Religion & $\begin{array}{c}\text { Religion influenced } \\
\text { Opinions? }\end{array}$ \\
\hline Opinions on Case Study 2 & Chi-square & 11.148 & 21.678 & 28.215 \\
\cline { 2 - 4 } & df & 1 & 1 & 1 \\
\cline { 2 - 4 } & Sig. & $.001^{*, b}$ & $.000^{*, b}$ & $.000^{*}$ \\
\hline
\end{tabular}

Results are based on nonempty rows and columns in each innermost subtable.

*. The Chi-square statistic is significant at the .05 level.

b. More than $20 \%$ of cells in this subtable have expected cell counts less than 5 . Chi-square results may be invalid.

Table 9 Pearson Chi-Square tests for Case Study 2. Tests include the link between participant's opinions on the case study vs their religion, whether they practice their religion and whether they believe their religion influenced their opinions. 
Pearson Chi-Square Tests (Case Study 2)

Experience with Terminal Illness

\begin{tabular}{|c|c|c|}
\hline \multirow[t]{3}{*}{ Opinions on Case Study 2} & Chi-square & 1.963 \\
\hline & df & 2 \\
\hline & Sig. & .375 \\
\hline
\end{tabular}

Table 10 Pearson Chi-Square tests for Case Study 2. Tests include the link between participant's opinions on the case study vs their experience with terminal illness.

Case 3:

Pearson Chi-Square Tests (Case Study 3)

\begin{tabular}{lllllll} 
& & Gender & Age & Ethnicity & Post Code \\
\hline Opinions on Case Study 3 & Chi-square & 2.520 & .187 & .591 & .001 \\
\cline { 2 - 6 } & df & 1 & 1 & 1 & 1 \\
\cline { 2 - 6 } & Sig. & .112 & .665 & .442 & .980 \\
\hline
\end{tabular}

Results are based on nonempty rows and columns in each innermost subtable.

Table 11 Pearson Chi-Square tests for Case Study 3. Tests include the link between participant's opinions on the case study vs their demographics, such as gender, age, ethnicity and post code.

\section{Pearson Chi-Square Tests (Case Study 3)}

\begin{tabular}{lllll} 
& & Religion & Practicing Religion & $\begin{array}{l}\text { Religion influenced } \\
\text { Opinions? }\end{array}$ \\
\hline Opinions on Case Study 3 & Chi-square & 9.668 & 20.138 & 16.689 \\
\cline { 2 - 5 } & $\mathrm{df}$ & 1 & 1 & 1 \\
\cline { 2 - 4 } & Sig. & $.002^{*, b}$ & $.000^{*, b}$ & $.000^{*}, \mathrm{~b}$ \\
\hline
\end{tabular}

Results are based on nonempty rows and columns in each innermost subtable.

*. The Chi-square statistic is significant at the .05 level.

b. More than $20 \%$ of cells in this subtable have expected cell counts less than 5 . Chi-square results may be invalid. 


\section{Pearson Chi-Square Tests (Case Study 3)}

Experience with

Terminal Illness?

\begin{tabular}{lll}
\hline Opinions on Case Study 3 & Chi-square & 5.226 \\
\cline { 2 - 3 } & $\mathrm{df}$ & 2 \\
\cline { 2 - 3 } & Sig. & .073 \\
\hline
\end{tabular}

Results are based on nonempty rows and columns in each innermost subtable.

Table 13 Pearson Chi-Square tests for Case Study 3. Tests include the link between participant's opinions on the case study vs their experience with terminal illness.

Case 4:

Pearson Chi-Square Tests (Case Study 4)

\begin{tabular}{lllllll} 
& & Gender & Age & Ethnicity & Post Code \\
\hline Opinions on Case Study 4 & Chi-square & .101 & .405 & .147 & .005 \\
\cline { 2 - 6 } & df & 1 & 1 & 1 & 1 \\
\cline { 2 - 6 } & Sig. & $.751^{\text {a }}$ & $.524^{\text {a }}$ & .701 & .946 \\
\hline
\end{tabular}

Results are based on nonempty rows and columns in each innermost subtable.

a. More than $20 \%$ of cells in this subtable have expected cell counts less than 5 . Chi-square results may be invalid.

Table 14 Pearson Chi-Square tests for Case Study 4. Tests include the link between participant's opinions on the case study vs their demographics, such as gender, age, ethnicity and post code.

\section{Pearson Chi-Square Tests (Case Study 4)}

\begin{tabular}{lllll} 
& & Religion & Practicing Religion & $\begin{array}{l}\text { Religion influenced } \\
\text { Opinions? }\end{array}$ \\
\hline Opinions on Case Study 4 & Chi-square & 15.220 & 11.733 & 12.599 \\
\cline { 2 - 5 } & df & 1 & 1 & 1 \\
\cline { 2 - 4 } & Sig. & $.000^{*, b}$ & $.001^{*, b}$ & $.000^{*, b}$ \\
\hline
\end{tabular}

Results are based on nonempty rows and columns in each innermost subtable.

*. The Chi-square statistic is significant at the .05 level.

b. More than $20 \%$ of cells in this subtable have expected cell counts less than 5 . Chi-square results may be invalid. 


\section{Pearson Chi-Square Tests (Case Study 4)}

\begin{tabular}{llr} 
& \multicolumn{2}{c}{ Experience with Terminal } \\
& & Illness \\
\hline Opinions on Case Study 4 & Chi-square & 5.570 \\
\cline { 2 - 3 } & df & 2 \\
\cline { 2 - 3 } & Sig. & $.062^{\text {a }}$ \\
\hline
\end{tabular}

Results are based on nonempty rows and columns in each innermost subtable.

a. More than $20 \%$ of cells in this subtable have expected cell counts less than 5 . Chi-square results may be invalid.

Table 16 Pearson Chi-Square tests for Case Study 4. Tests include the link between participant's opinions on the case study vs their experience with terminal illness.

\section{Pearson Chi-Square Tests}

\section{Opinions on Opinions on Opinions on Opinions on Dispensing CS1 Dispensing CS2 Dispensing CS3 Dispensing CS4}

\begin{tabular}{|c|c|c|c|c|c|}
\hline \multirow{3}{*}{$\begin{array}{l}\text { Believe they have been } \\
\text { taught aspects of } \\
\text { accompanied suicide on } \\
\text { their MPharm course? }\end{array}$} & Chi-square & .038 & .091 & 1.149 & .108 \\
\hline & df & 1 & 1 & 1 & 1 \\
\hline & Sig. & .845 & .763 & .284 & $.743^{a}$ \\
\hline
\end{tabular}

Results are based on nonempty rows and columns in each innermost subtable.

a. More than $20 \%$ of cells in this subtable have expected cell counts less than 5 . Chi-square results may be invalid.

Table 17 Pearson Chi-Square tests against participants' opinions on dispensing lethal medication for accompanied suicide vs whether they believe they have been taught aspects of accompanied suicide during their MPharm course. 